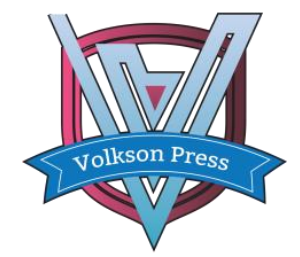

Contents List available at VOLKSON PRESS

Engineering \& Technology Innovations (ETI)

DOI : http://doi.org/10.26480/iceti.01.2017.147.150

\title{
Green Level Assessment of Electronic Products Whole Life Cycle based on the Modified TOPSIS
}

\author{
Juan $T A N G$ a, Zhi LIU a, * and Hong-lin $Z H{ }^{\text {a }}$ \\ a School of Management Engineering, Anhui Polytechnic University, \\ Beijing middle Street, Wuhu 241000, China \\ *Correspondent author: liuzhi0551@126.com.
}

This is an open access article distributed under the Creative Commons Attribution License, which permits unrestricted use, distribution, and reproduction in any medium, provided the original work is properly cited

\section{ARTICLE DETAILS}

\section{Article History:}

Received 02 october 2017 Accepted 06 october 2017 Available online 11 october 2017

\section{Keywords:}

Green manufacturing; Greening; Life cycle assessment; Modified TOPSIS; MA-OWA

\section{ABSTRACT}

The traditional manufacturing industry has brought rapid economic development while worsening environment in recent years. In order to realize low-carbon and sustainable development of manufacturing industry, the relevant national departments have proposed to build green manufacturing system and assess the products green level the as one of the most important indicators of this. From the perspective of the products whole life cycle, taking the electronic products as the research object and combining with the green manufacturing requirements, the green level assessment indicators are established. Taking the MA-OWA as weighting method, and using the modified TOPSIS method, the electronic products' green level was assessed. And the results show that the high green level and low environment impact of electronic products can be effectively selected, which is conducive to the sustainable development of the environment.

\section{INTRODUCTION}

In 2016,the Guidelines for the Implementation of Green Manufacturing Engineering (2016-2020 years)is jointly issued by the Ministry of industry and information technology, National Development and Reform Commission, Ministry of finance, and Ministry of science and technology in China. In order to implement the "Made in China 2025", strengthen the concept of green development, build a green manufacturing system, and achieve high efficient, clean, low-carbon recycling and sustainable development of manufacturing industry, these guidelines centre on demonstration and promotion of green transformation of traditional manufacturing industry, demonstration and application of resource cyclic utilization and green development, demonstration and application of technical innovation and industrialization of the green manufacturing, green manufacturing system construction pilot and etc, and then proposed specific work arrangement. To comprehensively promote green manufacturing system construction, the green products, green factories, green industrial parks and green supply chains should be regarded as the key objects of construction and development are pointed out in green manufacturing system construction. Therefore, the development of green products and the assessment of the products green level constitute an important part of the green manufacturing system.

Researchers have tried to do some work on it. Liu, G.F. and Liu, Z.F. (1997) proposes the green product and its assessment system frame. The product green degree was comprehensively evaluated with the using of assign weights by AHP and axiomatic design by Xiang, D. et cl. (2001). Ajukumar, V.N. and Gandhi, O.P. (2013) structured an integrated approach to evaluation green maintenance initiatives in design and development of mechanical systems, which is formulated as a multi-attribute decisionmaking model and the technique for order preference by similarity to ideal solution (TOPSIS) method. Fukushige, S., et cl.. (2012) developed are presentational scheme for the lifecycle scenario and proposed a support system based on the idea of the cognitive design process model. Anand, A. and Wani, M.F. (2010) presented an evaluation processing for product lifecycle design at the conceptual stage in terms of life-cycle design index. Yang, Q.Z. (2007) developed a life cycle assessment based sustainable product design for eco-design support and for product life cycle assessment analysis at early design stages, using which the designers can compare material and energy consumptions, and to assess environmental impacts of different end-of-life treatment options. Benetto, E., Dujet, C. and
Rousseaux, P. (2008) proposed an improved NAIADE method based on the fuzzy technique, and the uncertainty of life cycle assessment thus can be comprehensively analyzed. Based on the objective nature of the product "green", Liu, G.F. and Liu, Z.F. (1997) structured a multi-level comprehensive index evaluation system is constructed to comprehensively evaluate the greenness of the product. Relying on the life cycle of electronic products, Gao, L.X. (2009) evaluated the environmental impact loads at each stage.

All above the studies, some of them did not conduct research on specific product categories, some of them only proposed the index system and evaluation method without the combination of the specific examples, and the methods were not comprehensive. Based on the various stages of the product whole life cycle, this paper establishes the green level evaluation index of the electronic products whole life cycle with the combination of the requirements of green manufacturing, and uses the MA-OWA as the index weighting method to evaluate the product green level with the modified ideal solution (TOPSIS).

\section{Life cycle of the electronic products}

For the electronic product manufacturers, the analysis of the green manufacturing level should analyze from the whole product life cycle. The life cycle of electronic product includes product design stage, raw material selection stage, manufacturing stage, packaging stage, transportation stage, using stage, and product recovery and remanufacturing stage. Product design has an impact on the subsequent stages of the life cycle and interacts with them. For example, the modular design in product design allows the components to be rapidly replaced at the product manufacturing stage as needed, and it is easy to diagnose the product faults, maintain, repair, disassemble and recycle the product in the product recycling and re manufacturing stage. Therefore, in the product design, we must take into account the impact of each link on the ecological environment, at the same time, it is should be also consider how to maximize the products recycling so as to maximize the utilization of resources and minimize environmental impacts. Therefore, the green design level of the product largely determines whether the product life cycle is green.

The core of green manufacturing is the realization of " $4 \mathrm{R}$ " during the product whole life cycle, the " $4 \mathrm{R}$ " includes Reduce, Reuse, Recycle, 
Remanufacturing. Reduce is should be paid to reducing resource consumption and waste generation from the start of manufacturing. Reuse requires products and their components to be reused. Recycle requires the product generate reusable resources after use. Remanufacturing take high quality, high efficiency, energy saving, material saving, environmental protection as the criterion, repair and transform the waste products and their parts with the using of advanced manufacturing technology, so as to achieve the performance recovery and upgrading. Therefore, each link is associated with the " $4 \mathrm{R}$ " in a green life cycle of electronic product.

\section{The green level assessment system of electronic product whole life cycle}

The green level assessment system of the electronic products whole life cycle is an assessment index based on the electronic products life cycle, it includes green product design performance, green material selection performance, green production and transportation performance, green products using performance and green products recycling performance, as shown in Figure. 1.

(1) Green product design performance: Product design is oriented to the whole product life cycle, and plays an important role in improving the utilization of resources and the negative impact of the ecological environment. Therefore, green product design performance is a performance which reflected in the design process, and it can take into account every aspect of the life cycle to implement " $4 \mathrm{R}$ ".

Modular product design is a design method, which is based on the analysis of the functions, performance, specification and other attributes of the products. This method is divided and designed the corresponding modules and arranged them by the rapid combination of modules, and met different needs of the market. The modular design of electronic products can rapidly realize the combination design of different electronic components, simplify the product mix, improve production efficiency, reduce development costs, and benefit products' dismounting and recycling. Product ecological design is a design method, it fully considers the impact on the environment of the product whole life cycle in the product design stage, and puts the environmental factors into the product design, in order to reduce the environmental load in the products whole life cycle. Lightweight design is a design method, it minimizes the weight of product's structure, and meets the requirements of the service life and reliability. It can ensure the function and performance of electronic products, and reduce energy consumption and space demand under the given boundary conditions. Recyclable design is a design idea and method, it takes a series of questions into fully consideration, which includes the possibility of recovery of materials, the value of recovery, the methods of recovery, and the structural manufacturability of recycling. This method can achieve the best use of material resources and energy, and minimize the environmental pollution.

(2) Green material selection performance: Material selection includes manufacturing material selection and packaging materials selection, to a certain extent, the selection of material determines whether the product can be effectively recycled and the utilization of materials during processing, environmental loads resulting from waste products. The using proportion of green materials determines the green materials selection performance. Its indicators include the using proportion of environmentally friendly materials, the using proportion of clean materials, the using proportion of easy-processable materials and the using proportion of green packaging materials.

(3) Green production and transportation performance: In the process of product's manufacturing and transportation, processing technology, equipment, production and transportation mode will all affect the level of greening. The indicators include technological optimization capability, energy saving capacity in production process, emission reduction capacity in production process, processing equipment optimization capability, product reworking rate, and transportation pollution emissions.

(4) Product green using performance: The material consumption of sub products in the process is relatively small, but the energy consumption is more grievous, and will produce a lot of pollution emissions, including electromagnetic radiation, noise, calorific value, carbon dioxide. Therefore, the product energy consumption and product pollution emissions are used as indicators of green using performance of products.

(5) Product green recycling and remanufacturing performance: In the recycling and remanufacturing stage of the product's whole life cycle, the key of greening level is whether it can reduce the amount of waste and the impact on the environment when the product is damaged or failed, its green recycling performance is related to the material reuse proportion of the recycled product, the proportion of reused components and the reuse proportion of the product which has been repaired, and this paper set these as index accordingly.

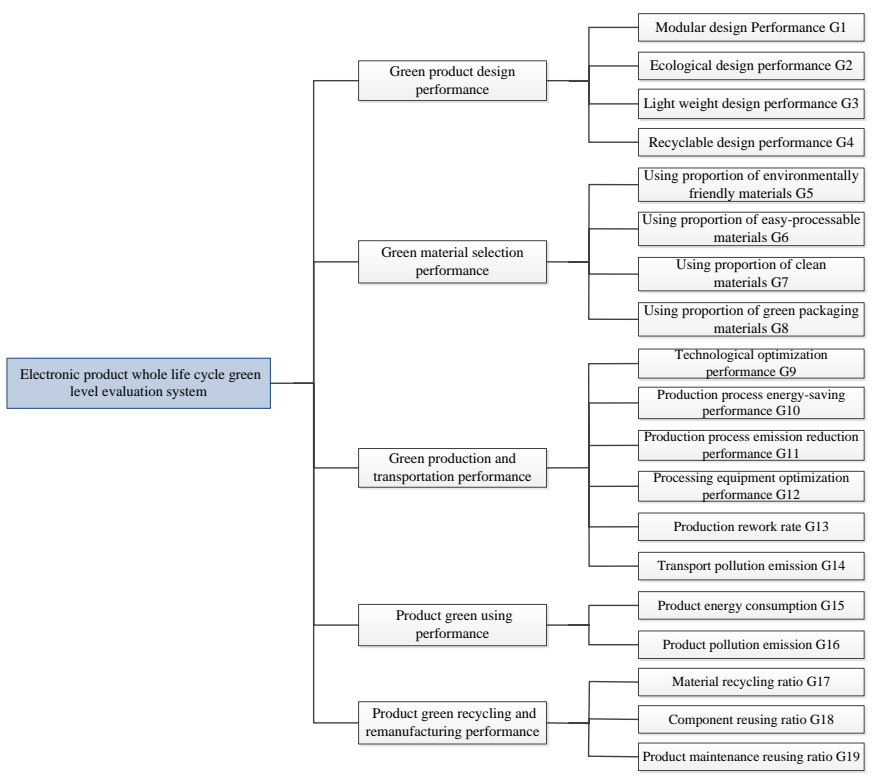

Figure.1. Greening level evaluation system of the electronic products whole life cycle

\section{Evaluation Method for Electronic Products Green Level Based on TOPSIS}

Sorting by means of the ideal solution and the negative ideal solution of the multi-objective decision problem is the basic principle of TOPSIS method, if there was a solution nearest to the ideal solution and far away from the negative ideal solution, and then this solution is the best solution in the aggregate of solutions.

\subsection{Defect improvement of the traditional TOPSIS method}

When the alternative $A_{j}$ is symmetric with respect to the ideal solution $r^{*}$ and the negative ideal solution $r^{-}$, because $s_{i}^{*}=s_{j}^{*}$ and $s_{i}^{-}=s_{j}^{-}$, so the advantages of $A_{i}$ and $A_{j}$ cannot be compared. Therefore, two weighted distance is used to express the distance from $A_{i}$ to the ideal solution $r^{*}$ and the negative ideal solution $r^{-}$:

$s_{i}^{*}=\sqrt{\sum_{j=1}^{n}\left[p_{j}\left(r_{i j}-r_{j}^{*}\right)\right]^{2}}, i=1,2, \cdots m ; j=1,2, \cdots n$
$s_{i}^{-}=\sqrt{\sum_{j=1}^{n}\left[p_{j}\left(r_{i j}-r_{j}^{-}\right)\right]^{2}}, i=1,2, \cdots m ; j=1,2, \cdots n$

Among them

$$
p_{j}=\frac{a_{j}}{\sum_{j=1}^{n} a_{j}}, j=1,2, \cdots, n \text { and } a_{j}=\left|\frac{r_{j}^{*}-r_{j}^{-}}{r_{j}^{*}}\right|, j=1,2, \cdots n .
$$

4.2 Evaluation model of electronic products green level based on modified TOPSIS

Building decision matrix $A$. There are $n$ indexes $\left(G_{1}, G_{2}, \cdots, G_{n}\right)$ and $m$ pending products $\left(A_{1}, A_{2}, \cdots, A_{m}\right)$ in the evaluation system of the electronic products life cycle. Pending evaluation product's $A_{i}(i=1,2, \cdots, m)$ value as $a_{i j}$ under the index $G_{i}(i=1,2, \cdots, n)$, thus the decision matrix $A=\left[\begin{array}{cccc}a_{11} & a_{12} & \cdots & a_{1 n} \\ a_{21} & a_{22} & \cdots & a_{2 n} \\ \vdots & \vdots & \cdots & \vdots \\ a_{m 1} & a_{m 2} & \cdots & a_{m n}\end{array}\right]$.

Using the MA-OWA operator to determine the weight of index $w$ : 
$w=\left(w_{1}, w_{2}, \cdots, w_{n}\right)(3)$

The normalization processing of matrix $A$ (4)

$d_{i j}=\frac{a_{i j}}{\sum_{i=1}^{m} a_{i j}}, i=1,2, \cdots, m ; j=1,2, \cdots, n$

4)

Normalized decision matrix $D$ as show:

$$
D=\left[\begin{array}{cccc}
d_{11} & d_{12} & \cdots & d_{1 n} \\
d_{21} & d_{22} & \cdots & d_{2 n} \\
\vdots & \vdots & \cdots & \vdots \\
d_{m 1} & d_{m 2} & \cdots & d_{m n}
\end{array}\right]
$$

Building a weighted normalized matrix $X$.

$X=\left[\begin{array}{cccc}w_{1} d_{11} & w_{2} d_{12} & \cdots & w_{n} d_{1 n} \\ w_{1} d_{21} & w_{2} d_{22} & \cdots & w_{n} d_{2 n} \\ \vdots & \vdots & \cdots & \vdots \\ w_{1} d_{m 1} & w_{2} d_{m 2} & \cdots & w_{n} d_{m n}\end{array}\right]=\left[\begin{array}{cccc}x_{11} & x_{12} & \cdots & x_{1 n} \\ x_{21} & x_{22} & \cdots & x_{2 n} \\ \vdots & \vdots & \cdots & \vdots \\ x_{m 1} & x_{m 2} & \cdots & x_{m n}\end{array}\right]$

Relative membership matrix $R$ as show

If $r_{i j}$ is a positive indicator

$\begin{cases}r_{i j}=\frac{x_{i j}-x_{j \text { min }}}{x_{j \text { max }}-x_{j \text { min }}} & x_{j \text { max }} \neq x_{j \text { min }} \\ r_{i j}=1 & x_{j \text { max }}=x_{j \text { min }}\end{cases}$

If $r_{i j}$ is a negative indicator,

$$
\begin{cases}r_{i j}=\frac{x_{j \max }-x_{i j}}{x_{j \max }-x_{j \text { min }}} & x_{j \max } \neq x_{j \text { min }} \\ r_{i j}=1 & x_{j \max }=x_{j \text { min }}\end{cases}
$$

Relative membership matrix $R$,

$$
R=\left[\begin{array}{cccc}
r_{11} & r_{12} & \cdots & r_{1 n} \\
r_{21} & r_{22} & \cdots & r_{2 n} \\
\vdots & \vdots & \cdots & \vdots \\
r_{m 1} & r_{m 2} & \cdots & r_{m n}
\end{array}\right]
$$

Calculating the ideal solutions $r^{*}$ and the negative ideal solutions $r^{-}$:

$r^{*}=\left\{\left(\max _{1 \leq i \leq m} r_{i j} \mid j \in J\right),\left(\min _{1 \leq i \leq m} r_{i j} \mid j \in J^{\prime}\right)\right\}=\left(r_{1}^{*}, r_{2}^{*}, \cdots, r_{n}^{*}\right)$

$r^{-}=\left\{\left(\min _{1 \leq i \leq m} r_{i j} \mid j \in J\right),\left(\max _{1 \leq i \leq m} r_{i j} \mid j \in J^{\prime}\right)\right\}=\left(r_{1}^{-}, r_{2}^{-}, \cdots, r_{n}^{-}\right)$

Among them, $J$ is a positive index set, and $J^{\prime}$ is a negative index set.

According to the formula (1) and (2), the two weighted distance from $A_{i}$ to the ideal solution $r^{*}$ and the negative ideal solution $r^{-}$are calculated. Calculating the closeness degree $c^{*}$ between the ideal solution of pending product $A_{i}$.

Sorting by the closeness degree $c^{*}$, the greater the value $c^{*}$, the higher the product greening level, and $c_{i}^{*}=\frac{r_{i}^{-}}{r_{i}^{-}+r_{i}^{*}}, i=1,2, \cdots, m$.

\section{Numerical Simulation Calculations}

The determination of decision matrix $A$ and the assignments of index weight. The four electronic product assessments on the whole life cycle are based on afore mentioned modified TOPSIS models. Divided into five grades of 1, 3, 5, 7 and 9, the qualitative indicators of evaluation system quantifies by expert evaluating method. The specific principle of the value is shown in Table 1.A questionnaire is designed at the same time, and the Likert measurement method is used to score the importance of the evaluation index. The values of the index are 5, 4, 3, 2, 1 and are on behalf of very important, important, general, not important, and very unimportant, respectively. And the MA-OWA operator is used to aggregate process the questionnaires and assign the weights to the metrics. The data and index weights are shown in Table 3.

Table 1. The qualitative indicators value principle of electronic products green life circle

\begin{tabular}{llllll}
\hline Index types & 1 & 3 & 5 & 7 & 9 \\
\hline Capacity & Very & Relatively & Normal & Relatively & Very \\
Energy consumption & weak & weak & & strong & strong \\
Emission & Very & Relatively & \multirow{2}{*}{ Normal } & Relatively & Very \\
& little & little & large & large \\
\hline
\end{tabular}

Table 2. The index scoring on the green level of electronics product while life circle

$\begin{array}{lllllllllllllllllll}X_{1} & X_{2} & X_{3} & X_{4} & X_{5} & X_{6} & X_{7} & X_{8} & X_{9} & X_{10} & X_{11} & X_{12} & X_{13} & X_{14} & X_{15} & X_{16} & X_{17} & X_{18} & X_{19}\end{array}$ \begin{tabular}{llllllllllllllllllll}
$A_{1}$ & 9 & 7 & 5 & 7 & 2 & 30 & 2 & 65 & 9 & 7 & 7 & 5 & 3 & 7 & 3 & 1 & 66 & 6 & 8 \\
\hline
\end{tabular} \begin{tabular}{llllllllllllllllllll}
\hline$A_{2} 7$ & 5 & 7 & 7 & 2 & 20 & 1 & 55 & 5 & 9 & 7 & 5 & 10 & 5 & 7 & 5 & 55 & 5 & 7 \\
\end{tabular} \begin{tabular}{lllllllllllllllllllll}
$A_{3}$ & 5 & 7 & 5 & 7 & 2 & 25 & 2 & 55 & 7 & 7 & 5 & 7 & 7 & 7 & 9 & 5 & 58 & 5 & 7 \\
\hline
\end{tabular} \begin{tabular}{llllllllllllllllllll}
$A_{4}$ & 7 & 5 & 9 & 5 & 1 & 25 & 2 & 60 & 7 & 9 & 7 & 5 & 5 & 3 & 7 & 3 & 50 & 5 & 7 \\
\hline
\end{tabular}

\begin{tabular}{|c|c|c|c|c|c|c|c|c|c|c|c|c|c|c|c|c|c|c|c|c|c|c|c|}
\hline & & $X$ & $I_{2} X$ & & v & ${ }_{4} X_{5}$ & $5 \quad X$ & $X_{6}$ & 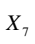 & $X$ & $X$ & - $X$ & $K_{10} X$ & $X_{11}$ & $X_{12}$ & & & $x$ & $r_{15}$ & $X_{16}$ & $X_{17}$ & $X_{18}$ & ${ }_{8} X_{1}$ \\
\hline$E_{1}$ & & 4 & 4 & & 5 & 4 & 3 & & 5 & 5 & 3 & 4 & 4 & 3 & 3 & 4 & 5 & 4 & 3 & 3 & 5 & 4 & 4 \\
\hline$E_{2}$ & & 3 & 4 & & 5 & 5 & 4 & & 3 & 5 & 2 & 4 & 5 & 4 & 4 & 5 & 4 & 5 & 3 & 3 & 4 & 5 & 3 \\
\hline$E_{3}$ & 4 & 5 & 3 & & 4 & 5 & 3 & & 4 & 4 & 3 & 5 & 4 & 4 & 4 & 3 & 5 & 5 & 4 & $t$ & 5 & 4 & 3 \\
\hline$E_{4}$ & 4 & 5 & 3 & & 5 & 4 & 3 & & 4 & 5 & 4 & 4 & 5 & 3 & 3 & 3 & 4 & 3 & 5 & 5 & 5 & 4 & 4 \\
\hline$E_{5}$ & 5 & 4 & 4 & & 4 & 4 & 5 & & 5 & 4 & 3 & 4 & 4 & 3 & 3 & 4 & 2 & 4 & 4 & 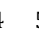 & 5 & 4 & 4 \\
\hline$E_{6}$ & 5 & 4 & 4 & & 5 & 4 & 4 & & 3 & 5 & 3 & 5 & 4 & 2 & & 2 & 4 & 5 & 4 & 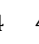 & 4 & 5 & 3 \\
\hline$w$ & $\begin{array}{l}4 \\
5 \\
5\end{array}$ & $\begin{array}{l}4.1 \\
25\end{array}$ & $\begin{array}{l}3.8 \\
75\end{array}$ & 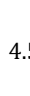 & & $\begin{array}{l}4.1 \\
25\end{array}$ & 3.5 & 4 & & 4.5 & 3 & $\begin{array}{l}4.1 \\
25\end{array}$ & $\begin{array}{l}4.1 \\
25\end{array}$ & $\begin{array}{l}3.1 \\
2\end{array}$ & 13. & & & 4.5 & $\begin{array}{l}3.8 \\
75\end{array}$ & $\begin{array}{l}4.8 \\
75\end{array}$ & $\begin{array}{ll}8 & 4 \\
5 & 2\end{array}$ & $\begin{array}{l}4.1 \\
25\end{array}$ & $\begin{array}{l}3 \\
5\end{array}$ \\
\hline $\bar{w}_{5}^{0 .}$ & & $\begin{array}{l}0.0 \\
54\end{array}$ & $\begin{array}{l}0.0 \\
51\end{array}$ & $\begin{array}{l}0 . \\
59\end{array}$ & & $\begin{array}{l}0.0 \\
54\end{array}$ & $\begin{array}{l}0.0 \\
46\end{array}$ & $\begin{array}{l}0.0 \\
53\end{array}$ & & $\begin{array}{l}0.0 \\
59\end{array}$ & $\begin{array}{l}0.0 \\
39\end{array}$ & $\begin{array}{l}0.0 \\
54\end{array}$ & $\begin{array}{l}0.0 \\
54\end{array}$ & $\begin{array}{l}0.0 \\
41\end{array}$ & $\begin{array}{l}0 . \\
46\end{array}$ & $\begin{array}{ll}.0 & 0 \\
6 & 5\end{array}$ & $\begin{array}{l}5.0 \\
54\end{array}$ & $\begin{array}{l}0.0 \\
59\end{array}$ & $\begin{array}{l}0.0 \\
51\end{array}$ & $\begin{array}{l}0 . \\
64\end{array}$ & $\begin{array}{ll}0 & 0 \\
4 & 5\end{array}$ & $\begin{array}{ll}.0 & 0 \\
4 & 4\end{array}$ & $\begin{array}{l}0.0 \\
46\end{array}$ \\
\hline
\end{tabular}

Table 3. The questionnaire descriptive statistical results and aggregate weight

The calculation of normalized matrix

$\left[\begin{array}{lllllllllllllllllll}0.32 & 0.29 & 0.19 & 0.27 & 0.27 & 0.30 & 0.25 & 0.28 & 0.32 & 0.22 & 0.27 & 0.23 & 0.12 & 0.32 & 0.11 & 0.07 & 0.29 & 0.27 & 0.26\end{array}\right.$ $\begin{array}{lllllllllllllllllll}0.25 & 0.21 & 0.27 & 0.27 & 0.27 & 0.20 & 0.19 & 0.23 & 0.18 & 0.28 & 0.27 & 0.23 & 0.40 & 0.23 & 0.27 & 0.36 & 0.24 & 0.25 & 0.23\end{array}$ $D=\left[\begin{array}{llllllllllllllllllll}0.18 & 0.29 & 0.19 & 0.27 & 0.27 & 0.25 & 0.25 & 0.23 & 0.25 & 0.22 & 0.19 & 0.31 & 0.28 & 0.32 & 0.35 & 0.36 & 0.25 & 0.27 & 0.25\end{array}\right.$ $\begin{array}{lllllllllllllllllll}0.25 & 0.21 & 0.35 & 0.19 & 0.19 & 0.25 & 0.31 & 0.26 & 0.25 & 0.28 & 0.27 & 0.23 & 0.20 & 0.13 & 0.27 & 0.37 & 0.33 & 0.25 & 0.26\end{array}$

The calculation of the weighting normalized matrix $X$, and finding the relative membership degree matrix $R$, then obtaining the ideal solution $r^{*}$ and the negative ideal solution $r^{-}$.

The $R$ is obtained according to the formula (6), (7) and (8).

$R=\left[\begin{array}{ccccccccccccccccccc}1 & 1 & 0 & 1 & 1 & 1 & 0.5 & 1 & 1 & 0 & 1 & 0 & 1 & 0 & 1 & 1 & 1 & 1 & 1 \\ 0.5 & 0 & 0.5 & 1 & 1 & 0 & 0 & 0 & 0 & 1 & 1 & 0 & 0 & 0.5 & 0.333 & 0 & 0.2 & 0.667 & 0 \\ 0 & 1 & 0 & 1 & 1 & 0.6 & 0.5 & 0 & 0.5 & 0 & 0 & 1 & 0.417 & 0 & 0 & 0 & 0.4 & 0 & 1 \\ 0.5 & 0 & 1 & 0 & 0 & 0.6 & 1 & 0.333 & 0.5 & 1 & 1 & 0 & 0.75 & 1 & 0.333 & 0.5 & 01 & 0.333 & 1\end{array}\right]$

The solutions $r^{*}$ and $r^{-}$are obtained according to the formula (10): $r^{*}=(1,1,1,1,1,1,1,1,1,1,1,1,0,0,0,0,1,1,1)$ and $r^{-}=(0,0,0,0,0,0,0,0,0,0,0,0,1,1,1,1,0,0,0)$.

The quadratic weighting distance $s_{i}^{*}$ and $s_{i}^{-}$are calculated according to the formula (1), and the closeness degree of green level is calculated. And Sorting the closeness degree from high to low, and the results are shown in Table 4.Calculations prove that the closeness degree of the four electronics are $c_{1}^{*}>c_{3}^{*}>c_{2}^{*}>c_{4}^{*}$, that is, the preferred order are: 
$A_{1}>A_{3}>A_{2}>A_{4}$, therefore the highest green level is $A_{1}$.

Table 4. The quadratic weighted distance and proximity degree of each product and its ordering

\begin{tabular}{|c|c|c|c|c|c|c|c|c|c|}
\hline $\begin{array}{l}\text { Product } \\
\mathrm{s}\end{array}$ & $S_{i}^{*}$ & $S_{i}^{-}$ & $c_{i}^{*}$ & $\begin{array}{l}\text { Sorti } \\
\text { ng }\end{array}$ & $\begin{array}{l}\text { Produc } \\
\text { ts }\end{array}$ & $s_{i}^{*}$ & $S_{i}^{-}$ & $c_{i}^{*}$ & $\begin{array}{l}\text { Sorti } \\
\text { ng }\end{array}$ \\
\hline$A_{1}$ & $\begin{array}{l}0.13 \\
2\end{array}$ & $\begin{array}{l}0.18 \\
4\end{array}$ & $\begin{array}{l}0.58 \\
2\end{array}$ & 1 & $A_{3}$ & $\begin{array}{l}0.14 \\
1\end{array}$ & $\begin{array}{l}0.16 \\
1\end{array}$ & $\begin{array}{l}0.53 \\
3\end{array}$ & 2 \\
\hline$A_{2}$ & $\begin{array}{l}0.15 \\
4\end{array}$ & $\begin{array}{l}0.14 \\
6\end{array}$ & $\begin{array}{l}0.48 \\
7\end{array}$ & 3 & $A_{4}$ & $\begin{array}{l}0.15 \\
3\end{array}$ & $\begin{array}{l}0.13 \\
8\end{array}$ & $\begin{array}{l}0.47 \\
4\end{array}$ & 4 \\
\hline
\end{tabular}

\section{Conclusion}

The MA-OWA operator is used to determine the weight of the index, and the modified TOPSIS method is used as the evaluation method, the evaluation system of the core elements of the green manufacturing is established based on the electronic product whole life cycle, it is conducive to the sustainable development of the environment, but there is a certain subjectivity in the quantification of qualitative indicators, which needs further study.

\section{Acknowledgments}

This paper is supported by the Humanities and Social Science Key Research Project of Anhui Province of China (No. SK2016A0109 and No. SK2017A0122) and the Philosophy and Social Science Program of Anhui Province, China (No. AHSKQ2016D18).

\section{References}

[1] Ajukumar, V.N. and Gandhi, O.P. (2013). Evaluation of green maintenance initiatives in design and development of mechanical systems using an integrated approach. Journal of cleaner production, 51: 34-46.

[2] Anand, A. and Wani, M.F. (2010). Product life-cycle modeling and evaluation at the conceptual design stage: A digraph and matrix approach. Journal of Mechanical Design, 132(9): 091010-091019.
[3] Benetto, E., Dujet, C. and Rousseaux, P. (2008). Integrating fuzzy multicriteria analysis and uncertainty evaluation in life cycle assessment. Environmental Modelling \& Software, 23(12): 1461-1467.

[4] Fukushige, S., Yamamoto, K. and Umeda, Y. (2012). Lifecycle scenario design for product end-of-life strategy. Journal of remanufacturing, 2(1): $1-15$.

[5] Gao, L.X. (2009). Life cycle assessmenton electronics and information products. Environmental science and management, 10:179-183.

[6] Liu, G.F. and Liu, Z.F. (1997). Green product and its evaluation system framework. Machinery design and manufacture, 4:10-12.

[7] Xiang, D., Duan, G.H., Wang, J.S. and Zhang, G.B. (2001). Integrated assessment of product green degree based on product system. Computer Integrated Manufacturing Systems, 8:12-16.

[8] Yang, Q.Z. (2007). Life cycle assessment in sustainable product design. SIM Tech Technical, 8(1): 57-64.

[9] You, J. and Zhou, H. (2016). General evaluation of product green degree based on product all-life cycle. Science and technology management research, 19: 60-63.

\section{About the Authors}

Juan Tang is faculty in the area of supply chain management and life cycle assessment in School of Management Engineering, Anhui Polytechnic University, China.

Zhi Liu is currently an lecturer in the in School of Management Engineering, Anhui Polytechnic University, China. His research interests include sustainable supply chain management and remanufacturing. $\mathrm{He}$ has over 10 publications in journals.

Hong-lin Zhu is a student in School of Management Engineering, Anhui Polytechnic University, China. 